\title{
THE EXCLUSIVE SOCIETY - ELDERLY PEOPLE AND ICT
}

\author{
Marc van Lieshout \\ University School of Informatics \\ Nijmegen, The Netherlands
}

\begin{abstract}
Elderly people are faced with the threat of exclusion - at least, this is what is formulated in various policy documents and public debates about the informatisation of society. The Dutch Rathenau Institute challenged this premise and has conducted a project that was aimed at analysing the relation between elderly people and ICT. It did so for three distinct roles of elderly people: the elderly worker, the elderly consumer and the elderly citizen. In this paper, the results of the project are presented and discussed.
\end{abstract}

\section{INTRODUCTION}

Since 1996 the Rathenau Institute (formerly known as the Dutch Organisation of Technology Assessment) has been engaged in a project about the elderly and the information society. The project was aimed at researching visions about the influence of information and communication technology (ICT) on the societal position of elderly people. A project team took responsibility for the project, co-ordinated by the author of this paper ${ }^{1}$. In this paper I will address the question whether the informatisation of society poses a serious threat for the societal participation of elderly people. After an introduction in which the societal role of elderly people, the societal context of informatisation and the notion of exclusion is elaborated, I present the results of the project. Three roles of elderly people were analysed by the project team: the elderly worker, the elderly consumer and the elderly citizen. For each role, exclusion processes were researched on the basis of a number of interviews with key members within each of the domains. The paper ends with a concluding section in which the overall dynamics of the influence of ICT and informatisation on the societal position and role of elderly people are taken together in a more generalising approach. 


\section{THE THREAT OF EXCLUSION}

Dutch society grows old, in absolute and relative figures. Today some $20 \%$ of the Dutch population is older than 55 years, and this is forecasted to increase to $30 \%$ in 2010 under conditions of a growing population (Timmermans 1997 p. 14). The societal problems of this double greying process are discussed at length in the media and in political circles. The debate runs from the costs of health care to problems of adequate housing to the political power elderly people might develop. In terms of the 'information society' it is questioned whether elderly people are able to follow the speed of contemporary socio-technical changes and be able to appropriate the skills and competencies needed to maintain a certain level of social inclusion. The European Green Paper 'Living and working in the information society - people first' identifies elderly people as a vulnerable group (European Commission 1996 p. 28). The Information Society Forum observes that in the near future "vast numbers of people [could be] living at the margins of the Information Society" (Forum Information Society $1996 \mathrm{p}$. $10)$.

While public attention on elderly people grows, this awareness is almost exclusively formulated in negative terms. Elderly people are not able to, do not want to, are not allowed to or do not have to ${ }^{2}$. Elderly people pose problems, due to their diminishing societal vitality. Information and communication technology seems to contribute to these problems. It refers to speed, to fast changes, to being young. Elderly people do not seem to be the people addressed by ICT and ICT products. Designers do not design for elderly people. ICT producers fear being associated with elderly people. Concepts such as 'Design for All' and 'Design for Old' do not cover much ground. Contrary to this 'appeal' of ICT the Green Paper 'Living and working ...' rightly observes that ICT could as well contribute to promoting the standard of life of elderly people, that it could be supportive to the level of independence of elderly people (in the sense of being able to take care of oneself) (European Commission 1996 p. 28).

While the foregoing seems to indicate a rather direct relation between technologies and their social implications, this is not how we conceptualise technology. Instead of presupposing a set of characteristics, which objectively determine a specific technology, we presuppose that both technology and its societal role are socially constructed. Actors attach meanings to technologies, and these meanings may vary over time, over 
place and over the actors. Technology and social context mutually influence each other. Technology does not exist outside the context in which it functions, and the way we perceive the materialisation of the technology determines our understanding of the specific technology. This implies that we can only study technologies within the context of use, and we should avoid talking about technologies as if they can be studied in isolation and have 'effects' or impacts on society. With this in mind, we can formulate the research question of the paper as follows: are we able to understand how elderly people and ICT relate to each other, and if so, how do we value this relationship? We will show that the social context in which elderly people function, and which is shaped by technologies and technological organisations, has potentially problematic aspects. Societal processes that configure today's situation bear the seeds of increasing societal isolation for elderly people in the future. With respect to commonly shared perceptions on the societal role of elderly people, we will show that these are based on false perceptions and outdated notions of elderly people.

In the following I will present the three main themes of our approach. I will start with the societal role of elderly people, continue with the societal role of informatisation, and then make some remarks about the concept of exclusion. Together these three themes form the framework for the discussion of the potential societal exclusion of elderly people due to processes of informatisation.

\subsection{Societal role of elderly people}

Elderly people today remain more vital than ever. Statistically, they live longer, they are healthier, possess more financial resources, are higher educated, etc. Being old today is quite different from being old twenty or thirty years ago. The importance of elderly people for society has however steadily declined. Illustrative for this decline is the still on-going trend of early retirement. Employment rates for elderly people - aged 55 or older are low. This is at least partly the result of a generally shared policy in the eighties when unemployment of young workers was unacceptably high. The then-formulated policy 'Young for Old' aimed to reduce the high percentage of unemployed youngsters. The severity of this problem was indicated by using phrases as 'the lost generation' for those who were in their twenties in these years. The results of this policy have been far-reaching. It has led to a societal structure in which less than $10 \%$ of people older than 60 years still work; it has led to a culture in which elderly people consider it a right to 
withdraw from working at the age of 55. The obligation to apply for a job stops at an age of 57.5. There is a general tendency - reflected by these processes - of a mutual withdrawal between society and elderly. Elderly people are allowed to withdraw themselves from active societal participation and engage themselves with the relatively closed and passive setting of an 'old day'. This 'ideology', that is still dominant in today's Dutch society, feeds the so-called deficit-models if the ageing processes. Getting old means - according to these models - acquiring deficits, mentally and physically. It means 'needed to be taken care of' (Lameiro-Garcia and Van Rijsselt 1992).

Opposed to these models we find the so-called activity-theories. These theories presuppose that elderly people are - up to a high age - able to compensate for mental or physical distress in ways that enable them to participate in most societal practices (cf. Salthouse 1996). Mental degradation - often thought of as 'natural decline' - is not typical before reaching a high age (cf. Baltes et al 1984). Today's elderly people remain socially active, at least in their own networks. Their withdrawal from other networks (e.g. politics, work) is usually induced by social 'expectations' or rules, and sometimes by legal obstructions.

So, while the deficit-models are based on an observation of societal practices around elderly people, the activity theory stresses the potentialities of elderly. The latter observes an imbalance between the expectations of society and the competencies of elderly people: a 'structural gap' (Riley 1987).

\subsection{The societal role of ICT}

Western society experiences a transition from an industrial society to an information society. Key to this transition is the unlimited availability of the chip, the on-going increase of processing capacity of the chip, the availability of global networks and the on-going sophistication of tools (software) to control the flows of information (cf. Freeman \& Perez 1988, Dordick \& Wang 1993). Others argue that this view of ICT is too much based on economic parameters, and fails to deal properly with societal change processes (cf. Webster 1995). Both perspectives nevertheless seem to accept that something is changing, be it in economic terms or be it in social terms. A perspective that I would like to put forward is the one in which it is not the artefact per se that is basic to the change process (the 
chip) but the changes in organising societal processes that are enabled by electronic networks in and between organisations and individuals. It is the process of informatisation that enables changes in the organisation of societal processes. The technical core of this process of informatisation is formed by the electronic gathering, processing, storage and distribution of data. Two ideal-types of informatisation may be discerned (cf. Zuurmond 1994): the global and universal type and the local and contextual type. In the first ideal-type, a strengthening of traditional bureaucratic elements occurs, such as standardisation, centralisation, formalisation, hierarchisation, and specialisation. In the second ideal-type personal preferences, flexibility, creativity, and individual responsibility are of prime importance. In studying a number of social security offices, Zuurmond found that the first type is more prevalent than the second. This means that people will have to adapt to the standards of the ICT-system/environment. The electronic contact points that form the interface between the system and the user (be it an electronic cashing system or an organisational information system) configure the user. The design of these contact points may imply certain behavioural parameters that will be more favourable to certain users than to others. Usually, for instance, they imply active behaviour of the user. They imply a certain responsiveness, a time frame in which the user has to respond at the cost of being logged-out. They imply a learning-by-doing or learning-by-using attitude, a willingness to interact with a maybe unknown system. Characteristics such as these seem to favour young people more than old, for various reasons. Young people grow up in a world that for them is 'naturally' related to ICT. Older people know this is not the case. Older people may have experienced several changes in their working situation or in their daily living that might be related to changes in the technological basis. They may feel more alienated to newer forms of technology ${ }^{3}$.

\subsection{Processes of exclusion}

One of our reasons for researching the exclusion of elderly people in relation to ICT was the rhetoric that seemed to underlay the notion of exclusion. It was stipulated that exclusion was an inevitable side-effect of modernisation. Not only elderly people, but women and lower educated people would be threatened by social exclusion as well. In a situation where vast numbers of the population are threatened by social exclusion it is of course of great importance to be as precise as possible in defining what we mean by exclusion. With respect to elderly people some preliminary remarks can be made. First of all, it is a gross generalisation to speak about the elderly 
people. We must be careful. We use a socio-demographic variable (age) for identifying a part of the population that is extremely heterogeneous. Individual characteristics increase with growing age. A woman of fifty-five years old may be quite different from a man of eighty-five in many respects. One of the reasons to use age as a discriminator, however, is that society implicitly or explicitly uses norms that are related to age. In work for instance, reaching the age of 65 means being expelled from the active workforce. Reaching the age of 70 quite often means being expelled from exercising administrative and political functions. Many societal organisations use this age as the limit for official positions within their organisation. But other more implicit social rules have built-in agesensitivities as well, such as a Dutch magazine that is only sent to 'young' academics who are still in the process of finding a suitable job ${ }^{4}$.

The term exclusion implies a negative connotation. Exclusion is a situation that should be avoided. This does not necessarily have to be so. When exclusion is a self-determined situation (for instance the hermits of former days) it seems to be a situation to be respected. With respect to ICT the socalled 'Information Want Nots' might be identified as a group whose members consciously withdraw from use of ICT. So, exclusion becomes a problem only when specific circumstances are met. Only when causes, that are difficult to be influenced, lead to systematic restrictions of individual opportunities (and this is so for an identifiable group) does it seem appropriate to speak about exclusion as a societal problem (Schuyt 1997). The project team that was responsible for the project added to this definition that exclusion is not a situation that will occur overnight. It usually is an incremental step-by-step process that eventually leads to a situation in which people are effectively excluded from societal participation on one or more societal domains (work, leisure, political and administrative functions). The process is influenced by societal norms and rules that restrict individual choices. What remains to be shown is how ICT and informatisation influence these processes of step-by-step exclusion and in what matter.

\section{ELDERLY PEOPLE IN THE INFORMATION SOCIETY}

The project team identified three societal roles for elderly people that were worthwhile to examine more closely: the elderly worker, the elderly consumer and the elderly citizen. By interviewing experts on these three domains, the panel collected as much relevant views as possible. The results 
of these hearings are presented below, followed by a reflection on the trends and processes that showed up.

\subsection{The elderly worker}

According to the interviewees, ICT and informatisation do not bear a direct relationship with the on-going trend of early retirement of elderly workers. That elderly workers still retire at relatively young age (most between 55 and 60 years old) is an undisputed fact. The interviewees attributed this to the policy of the eighties that was aimed at getting young people at work. It was suggested on the other hand, that there are some indirect effects related to ICT and informatisation that put elderly in a disadvantageous position. First, informatisation is essentially a process of on-going re-organisation. This introduces uncertainty within an organisation. It introduces an increased need for flexibility on part of the working force. It introduces the need for continuous education and schooling. Being close to retirement, however, the need for an update of skills and competencies diminishes. The final phase of one's life as a worker is characterised by a transition of personal development within a working career to personal development outside a working situation. The need for job rotation diminishes at the end of a career. Each re-organisation introduces psychological stress; older workers will have statistically experienced more re-organisations than younger workers. From the side of the organisations not much is done to keep elderly workers aboard. Management tools such as age-sensitive personnel management and schooling activities hardly focuses on elderly workers. Statistics show that the share of elderly workers in qualified vocational courses has increased over the past five to ten years, but still lags far behind other age groups (Timmermans 1997 p. 34). The knowledge intensity of labour increases. The skills needed to operate optimally within an organisation have shifted from manual skills to intellectual or knowledge based skills. In general, new information systems need specific training courses. Elderly workers face the prejudice that they are not able to appropriate the knowledge that is needed to operate these systems. It is argued that elderly people lose control capacity, lose quickness of action, lose capacity to deal with big flows of information. Loss of mental capacities generally does however not occur before a high age, though some specific skills seem to decline (Baltes et al 1984). And, as a surplus, elderly workers have quite a repertoire of compensation mechanisms. Several interviewees emphasised that elderly people are perfectly able to learn about new ICT, if only training courses would take the peculiarities of specific 
target groups into account (familiarity with modern training courses, possession of basic skills, identification with learning issues, etc.).

One of the effects of the negligence of the competencies and capacities of elderly people is the occurrence of experience concentration, which means that workers simply stick to doing the kind of activities they are doing, or they are presumably good at a certain period in their active career. Active interference of personnel managers usually stops at a relative young age, when workers are in their forties. Impulses to accept a new task that needs other skills, diminishes over time. This rigidity or inflexibility should thus not be related to age but to styles of personnel management that fail in guiding workers of different ages in personnel career paths. This kind of self-fulfilling prophecy abounds in labour settings. The increasing dependency within organisations upon ever-changing information and communication technologies, and the on-going informatisation of the organisation, add to conflicts related to the 'employability' of elderly workers, undeniably leading to a negative image (inducing a negative selfimage as well) of the competencies and potentialities of elderly people. Aspirations of elderly workers are neglected and when taken into account, are considered to point in the direction of early retirement. In this way, the societal norm of a profitable early retirement is reconfirmed by elderly people themselves. This gives rise to the paradoxical situation that though increased vitality of elderly people theoretically points in a direction of prolonged professional careers in combination with fine-tuned personnel management, in practice it happens the other way around: shortening of professional careers and - due to a lack of age-sensitive personnel management - a re-confirmation of the trend toward early retirement.

It should be noticed that awareness about the specific position of elderly workers is growing. This is partly because the (financial) need to keep elderly people at work is growing, at the cost of unbearable financial burdens, but also because the paradoxical character of today's situation is more and more recognised. Employability arrangements (included possibilities of demotion ${ }^{5}$ ) become more flexible, thus contributing to a maturing of the third life cycle phase: the phase after retirement when one is still vital (physically and mentally) and able to deploy new initiatives. The debate about the concept of life long learning is not solved yet, but has led to a growing attention for what this concept means when you are in your fifties, and close to retirement. Combined with a recognition of the positive qualifications of elderly people (more than today's focus on the qualities 
they seem to lack) these developments offer chances and opportunities that might be profitable for both elderly people and society.

\subsection{The elderly consumer}

Some $25 \%$ of the Dutch population is aged 55 years or older. This in itself makes this group an interesting market group. It is a group with very specific characteristics: incomes are relatively high, children have left the parental home, or are about to do so, there is quite a lot of free time to spend, while vitality is on average satisfactory ${ }^{6}$. These factors support the attractiveness of developing products and services specifically for elderly people. Up till now such a market does not exist, however. Interestingly enough, both parties (suppliers and consumers) deny the need for such a market. Suppliers generally do not want to be associated with products or services for elderly. They fear this association is negative for their corporate images. Consumers associate products or services for elderly people with negative qualifications such as dull or grey. The producer thus must be dull and grey itself. Being a producer of products for elderly people might have reverse effects in other markets. A typical Dutch example of this stereotyping in practice can be found in the product developed by the one and only Dutch car manufacturer, DAF. In the late sixties, DAF managed to produce an engine that was highly innovative in those days. It had a differential system that was fully automatic. So, no gears and clutches were needed. Instead of being hailed as a liberating and innovative answer to cardriving, the car turned out to be associated mainly with elderly women who were cautious car drivers. This negative stereotyping has never left DAF. Even today DAF is mainly associated with this image of dull, grey and slow car driving. But elderly people are reluctant themselves to buy products that are designed specifically for elderly people. They try to avoid the negative stereotyping that comes with age: physical impairments, mental distress, dumb, grey, slow, no sex-appeal. While marketing departments collect all kind of information about consumer groups, knowledge about aspirations of elderly people is still almost absent. Interviewees working for big Dutch companies in the field of ICT admitted that interest about elderly people was very low in their organisation. In some cases, the interviewees were really pioneering within their organisation to increase awareness for the market potentials of the elderly people. They complained about the fact that they had to cover $25 \%$ of the total consumer population with a staff of no more than ten to twenty people. 
ICT-products and services usually require a certain skill of the user. They also require a kind of 'investigative mood': though for instance application programmes (such as a word processor or a browser) will always be delivered with a manual, in general these programmes expect a 'learning by doing' attitude of the user. A recent survey in which uses and attitudes towards a range of ICT-based services and products was researched, shows that use of daily services such as electronic cash dispensers, electronic ticket services (available at railway stations), and products such as video-recorders decreases with age (see Table 1 for an overview). Though explanations for age-related differences are still speculative, some remarks can be made. First, services that require programming skills (such as a video-recorder or the electronic tablets at railway stations) pose problems to elderly people. Second, the required style of 'learning by doing' is alien to elderly people, who were raised with machines that could dramatically fail when the wrong button was pushed. This latter gives rise to suggesting generation differences that might be based on differences in attitudes towards technology: each generation is raised in a period with specific, paradigmatic, technologies. These paradigmatic technologies (e.g. the PC, the telephone, the car) communicate specific uses and non-uses. Paradigmatic technological examples for elderly people relate to handle-and-stick technology that required precise operation procedures (cf. note 3 ).

Table 1. Digital skills (taken from Doets \& Huisman, 1997)

\begin{tabular}{|c|c|c|c|c|}
\hline (Percentages) & $<50$ & $50-56$ & $57-63$ & $64-70$ \\
\hline Ownership of PC & 53 & 46 & 27 & 18 \\
\hline Use of PC (regularly/often) & 39 & 20 & 12 & 6 \\
\hline Control of use (hardly/absent) & 36 & 69 & 79 & 83 \\
\hline \multicolumn{5}{|l|}{ Personally experienced deficit } \\
\hline Absent & 42 & 39 & 33 & 39 \\
\hline Moderate & 32 & 21 & 21 & 16 \\
\hline Relevant & 26 & 40 & 46 & 45 \\
\hline Use of ATM (regularly/often) & 83 & 64 & 56 & 43 \\
\hline Control of use (hardly/absent) & 9 & 19 & 23 & 45 \\
\hline \multicolumn{5}{|l|}{ Personally experienced deficit } \\
\hline Absent & 94 & 82 & 77 & 68 \\
\hline Moderate & 4 & 8 & 9 & 5 \\
\hline Relevant & 2 & 10 & 14 & 27 \\
\hline \multicolumn{5}{|l|}{ Buying a train ticket from a } \\
\hline ticket machine (regularly/often) & 25 & 9 & 12 & 8 \\
\hline Control of use (hardly/absent) & 54 & 79 & 76 & 83 \\
\hline \multicolumn{5}{|l|}{ Personally experienced deficit } \\
\hline Absent & 76 & 68 & 64 & 66 \\
\hline Moderate & 11 & 17 & 17 & 9 \\
\hline Relevant & 13 & 15 & 19 & 25 \\
\hline
\end{tabular}


Though these factors might contribute to positioning elderly people as 'laggers', as those who will be latest in adopting new gadgets, at a closer look this correlation does not hold. Elderly people could better be defined as critical consumers. They are critical towards the value-added benefits of the new gadgets. Factors that contribute to added value in certain circumstances (for instance the possibility to collect money from Automated Teller Machine 24 hours a day) is not necessarily an advantage when you have all the time of the world and feel more comfortable in the closed surroundings of a banking office than in front of a machine located at a cold and windy place, with a screen that is hardly visible because of all the scratches on it, and with an operating procedure that is barely fault-tolerant. But when an application is offered that fits specific needs, elderly people will not hesitate to buy. They are sensitive to service that is offered and they perceive service as added value. So, while table 1 shows a clear lag of elderly people when it comes to daily uses of electronic cards or personal computers, this does not necessarily mean that they are not interested. They are, as for instance the interest in electronic consumer products at a yearly Elderly Fair shows, but they need dedicated addressing.

The attention for elderly people as a consumer market grows. Designers experiment with concepts such as 'Design for Old' and 'Design for All'. The first concept is based on the idea that designing for elderly people might introduce specific requirements to the design process and the products and services to be designed. The second concept presupposes that there is always a bigger circle of people that might profit from a specific design that focuses on elderly people. Concrete results of these approaches are very rare, however. Problems relate to the complicated mix of factors that determine the use of a product or service, and the heterogeneous constitution of any ensemble of elderly people. Differentiation amongst elderly people is high, troubling any general approach. Customised services are a prerequisite for any successful marketing approach.

The primordial question remains whether elderly people are excluded from consumer markets because of their age. Contrary to the situation in the labour market, where societal exclusion processes are visible, the consumer market is less transparent on this aspect. Some observations can be made. First, the invisible hand of the market fails to do its job. The segment of elderly people is quite interesting from a market perspective but suppliers and consumers keep each other in a dead-lock situation. Knowledge on how to design for elderly people is limited. Experience with design for old is scarce. There is a general reluctance on the side of the commercial 
companies to experiment with products and services dedicated to elderly people. But this in itself does not lead to societal exclusion. Second, most services and products do not clearly facilitate or hinder societal participation. Banking offices are still open, railway stations do have staffed ticket offices. On this issue there is however reason for concern. Since electronic cashing systems, ticket delivery systems, etc., are economically more efficient and since they offer to those who are familiarised with these system greater flexibility in arranging their affairs, there is a tendency towards replacing staffed services by electronic ones. The informatisation of many societal services might in the end lead to a sparseness of non-digital 'alternatives'; this might be rather harmful to elderly people. Elderly people - taking the figures of table 1 as indication - are in a less favourable position in using these electronic variants than others. In case availability of a service is considered to be vital for societal participation, the service should somehow be guaranteed for all, even when this includes its nonelectronic variant ${ }^{7}$. This is more than a design question, even when design is taken in its broadest meaning. This is a political issue, that must be solved through political negotiations.

\subsection{The elderly citizen}

The third role of elderly people we examined was their role as citizen ${ }^{9}$. The structural tension between society and elderly people that we mentioned in paragraph 2, may be the most prominent in this role. Society does not expect much from elderly people, they are allowed to withdraw from public life. This allowance to withdraw is however counteracted by the observed societal participation of elderly people. More than 600,000 elderly people (approximately $15 \%$ of Dutch population aged 55 or more) are member of one of the many organisations for elderly people. In 1994, two political parties for elderly people were elected to the Dutch parliament. Elderly people are active as volunteers in societal organisations up till a high age. Notwithstanding this attitude, the societal position of elderly people is not very strong. In political and organisational forums, their participation is limited and usually formally restricted when the age of 70 has been reached. In this section we will address the question whether processes of informatisation influence the societal participation of elderly people positively or negatively. We will do so along two different perspectives: elderly people in their role as customer of public services; and elderly people in the public sphere. 
As stipulated, today's way of informatisation is leading to an infocracy (Zuurmond 1994). Informatisation is used to strengthen the bureaucratic position of government, to assist in control activities directed at fighting fraud and criminality. The predominant form of informatisation, the global and universal form, increases the control instruments of management at the cost of the people 'down under'. These would profit most from a local and contextual form of informatisation: a form that allows for creative and finetuned uses of resources, equipment, services and control mechanisms, that enables individual responsibility, that is more customer oriented, etc. On a modest scale, the Dutch government deploys initiatives that may counterbalance the Weberian-oriented form of informatisation (i.e. the hierarchical, top-down form). The Dutch Ministry of Internal Affairs has initiated an experiment with a number of one-stop counters. Each counter addresses a specific theme. Back offices and front offices of various departments within one municipality are virtually combined in one central counter. Information networks, databases and intelligent search strategies are used to combine the dispersed data into an information service that is fine-tuned to the requirements of citizens. They no longer need to wander through the town hall, searching for the proper order of counters to be followed, but they are served at one place. One of the thematic counters that is developed according to this strategy, is a counter for elderly and handicapped people. Though the combination of elderly and handicapped people is not a very lucky one (being old apparently is a handicap; handicapped apparently are old) the attempt to optimise the information in one interface between the government and the (elderly) citizen is a sympathetic one. As such, it is an example of using information about citizens for citizens. The information imbalance between public authorities and citizens as customers is not yet solved however. Optimising a service does not necessarily shift the power balance between two parties. Citizens remain dependent on the quality of information collected by (local) authorities, and the specific uses of this information. The consequences of the existing imbalance is not a typical problem for elderly citizen. Everybody who 'needs' a public service is confronted with this imbalance. It only could be argued that the number of exchanges with local authorities increases with age.

But it is not only the interface that changes. It is not only the fact that computers instead of people mediate communication in more and more situations that people have to get used to and be trained in. It is also the change in the organisation of the 'system' of communication, the change in the mode of communication. This mode has changed form a collective one 
to an individual one. The computer-mediated communication all too often addresses individuals. Information that is stored is information that is related to specific individual circumstances. Next to the advantages this offers (for instance a possible fine-tuning of social welfare arrangements) it presupposes individual competency in coping with this kind of communication process. This is a skill that must be learned, and that may need more and more careful considerations in case of elderly people. It also needs attention from within the public offices. Some interviewees stated that commercial organisations have developed strategies, unknown within public offices, to inform people of whom they collect personal data (usually by means of a customer card) on a regular base about the information they have collected about them. One interviewee told about a public office in Britain that started to inform citizens about specific rights they had in specific circumstances. When it turned out that too many citizens took notice of their rights, the campaign was brought to a halt; it would be too expensive to fulfil the obligations towards all citizens who had a formal right on a financial subsidy. In a situation where the information balance between public authorities and citizens is such that the latter group is dependent on how they are informed, the Weberian mode of informatisation prevents the citizens from getting what they are entitled to. Again, this is not typical for elderly citizens, but since they have more contacts with public offices they may experience that the information balance does not work to their advantage $^{10}$.

The second role is the role of elderly citizens as members of a democratic society and as citizens in a democratically organised society. As member of a society, elderly people should be able to engage in democratic institutions and means as much as any other person. As long as there is a general reluctance on the side of the public authorities themselves to use ICT in creating electronic public forums, and as long as experience with these new forms of electronic democracy is limited, there is no need to worry about the possible exclusion effects of these media on the societal role of elderly people. Experience with electronic debating forums are still scarce, and the results so far are not very encouraging. And our prime minister, aged 60, showed in a recent television programme that he is barely familiar with modern technologies. He was invited for an e-mail discussion with a twelve year old girl because of the closeness of the next elections, and he politely asked whether this would require his presence every week at the television studio. We might argue that socially accepted images of elderly people according the 'deficit' models must yet be considered to be more harmful to 
the societal role of elderly people than electronic experiments in which elderly people are hardly involved.

In a similar vein there is no need to exaggerate the general role of ICT and informatisation in organising a 'digital' public domain at present. And as long as there is confidence in guaranteeing alternatives, it might be argued that there is no specific need to worry about the effects of informatisation on the societal participation of elderly people either. This however, is based on a defensive attitude. It is based on an approach in which elderly people are considered to be late adopters, or laggards. In organising 'cyberspace' elderly people should be taken in. They may profit as much from the opportunities of new media and new ICT as others. One interviewee told about an experiment with e-mail that has been performed in two different houses for the elderly. In one house it turned out to be a complete failure, while in the other house it showed to be rather successful. One of the critical factors in this experiment was the simple fact that there must be someone to e-mail with. In one house the 'sample' of elderly people was such that email communication with relatives, friends, or grandchildren was difficult since the other party was not on-line, while in the other house this turned out to be no problem. This experiment showed (again) that it is not the tool itself that is the problem but the social configuration in which the tool is placed.

A final example is the initiation of a Dutch website for elderly people: SeniorWeb. This is an initiative of the Dutch Organisation for Elderly People and Europe, an ambitious organisation of elderly people that takes the European Union as a channel for combining efforts with other elderly organisations throughout Europe. They took the US-based SeniorNet, which is a very successful website for elderly people in the US, as their exemplar. There are interesting differences to be noted between a website for elderly people and a 'modal' website that aims at younger people (e.g. the elderly website uses softer colours, and has poems on its site) but the main point to be made is that these people perceive modern ICT-based tools such as the Internet as a perfect medium to realise their objectives: mediating between (elderly) people from different European countries. So, elderly people are able to take the lead in using new ICT for their own purposes in a manner that makes them innovators instead of laggards. 


\section{CONCLUSIONS}

In the foregoing paragraphs we have presented the results of our search through the relation between elderly people and processes of informatisation. This has produced some typical results. First, there is a tendency to focus on negative qualities of elderly people: the view prevails that elderly people are not able to, and not willing to, profit from the fruits of technological progress. External factors, such as how information processes are organised, how opportunities and restrictions following from the typical organisation of these processes are distributed, are neglected as explanatory factors for the less than average use of ICT tools and means. Adding to the prevailing negative perception of the qualities of elderly people is the existence of strong negative stereotypes of elderly people. Elderly people are usually related to issues of care and cure, and seldom to issues of independence and vitality. The combination of elderly and handicapped people illustrates the deficit-approach that is still predominant ${ }^{11}$.

We started the project with the objective to research the societal position of elderly people in relation with developments in ICT and new media. We have looked whether informatisation contributes to processes of societal exclusions, i.e. whether these processes lead to systematic restrictions of individual opportunities for a significant and identifiable part of elderly people. We have stated that the group of elderly people is a very heterogeneous group, that makes it difficult to identify specific subgroups. Still, we think a few lessons might be learned from our research. First, in working situations processes of societal exclusion occur, due to a combination of factors. ICT and informatisation contribute in construing a playing field that supports early retirement and that rewards negligence of capacities and competencies of elderly people. In consumer markets it is a failing design process in combination with a double dead-lock that constitutes the social script in which elderly people are neglected as an interesting consumer group. We have stated that this in itself does not lead to societal exclusion. Only when services, which are considered to be vital for societal participation, get out of reach do problems evolve. We have argued that due to informatisation this problem may get worse in time, since many personally mediated services are replaced by computer mediated services. Finally, in the public sphere, problems arise due to informatisation but these can not be identified as societal exclusion of elderly people. Informatisation processes could be improved to include fine-tuning of services to individual needs and requirements. The Weberian mode of informatisation should be replaced by a more egalitarian approach that takes 
the information needs of people as a starting point. The two-sided character of technology enables active construction of societal practices in which elderly people are optimally able to participate. It also enables a more positive attitude towards elderly people and towards their contribution to society.

\section{NOTES}

1 The paper does not necessarily reflect the view of the Rathenau Institute on this issue. Cf (Rijsselt \& Weijers 1997) for a detailed elaboration of these four mechanisms.

This has been one of the arguments used by employers in reorganisations to replace older personnel by younger. It refers to the presumed existence of so-called technique generations: the way how people envision technology is dependent on the dominant technological frame that existed when you are educated or trained. This vision determines the way how new technologies will be met (cf. Rijsselt \& Weijers 1997, p.85).

4 It may be interesting to note that these implicit and explicit boundaries are questioned today. Only recently a law has been enforced that prohibits the use of age as a criterion in job applications. Other trends indicate a growing sensitivity to the usefulness of age as discriminator as well.

5 Demotion is the opposite of promotion: stepping down within one's own working biography.

6 We have to be careful. This picture describes what is sometimes called the golden generation. It should be noted that this golden generation encompasses not more than $25 \%$ of the total elderly population. Though vitality remains high up till a relatively high age, elderly people from 75 years or older increasingly face physical ailments; specific groups such as widowed women of high age are financially not well-off either.

7 We must not conceal the fact that determining what precisely should fall under the heading of 'universal services' is a very difficult and by no means unambiguous task. Especially since societal participation of elderly people seems not to be hindered at this moment (because non-electronic alternatives are still abundantly available) we may argue that the drive to make a list of universal services is rather low. But changes in the daily arrangements of practical affairs may introduce the necessity to start discussing whether the list should be enlarged.

8 The Rathenau Institute has dealt with the issue of universal service in a forerunner of the project described in this paper. In its project related to the national Action Programme on Electronic Highways it came to the conclusion that defining which services should be universal services is a matter of politics, and is always open to renewed negotiations (Rathenau 1996). In (Lieshout et al. 1997) we have elaborated this role in depth. In this paragraph we stick to the headlines.

An interviewee showed some official letters that were sent to widowed elderly people. While all the information that was asked for in the letters, was available at the office, the recently widowed people were threatened with severe sanctions when they failed to give the required information within a certain period of time. 
11 As undoubtedly will have become clear, this stereotyping works the other way as well: handicapped people are stereotyped on base of a handicap, which they need not necessarily perceive as handicap.

\section{REFERENCES}

Baltes, P.B., Dittmann-Kohli, F. \& Dixon, R. A. (1984) New perspectives on the development of intelligence in adulthood: toward a dual-process conception and a model of selective optimisation with compensation. In Baltes, P.B. \& Brim, O.G. (eds.) Life-span development and behaviour. Vol. 6. Academic Press, New York, pp. 33-76.

Doets, C. \& Huisman, T. (1997) Digitale vaardigheden - de stand van zaken in Nederland. CINOP, Den Bosch.

Dordick, H.S. \& Wang, G. (1993) The information society - a retrospective view. Sage Publications, London.

European Commission (1996) Living and working in the information society: people first: Green Paper. COM (96)389. European Commission, Brussels.

Freeman, C. \& Perez, C. (1988) Structural crises of adjustment: business cycles and investment behaviour. In Dosi, G., Freeman, C., Nelson, R., Silverberg, C. \& Soete, L. (eds.) Technical change and economic theory. Pinter Publishers, London, pp. 38-67.

Forum Information Society (1996) Networks for people and their communities: making the most of the information society in the European Union: first annual report. Brussels.

Lameiro-Garcia, L. \& Rijsselt, R.J.T. van (1992) Sociale participatie van ouderen in Nederland: inventarisatie en analyse van een onderzoeksterrein in sociale interventie 1992/2: pp. 83-93.

Lieshout, M. van, Weijers, T. \& Rijsselt, R. van (1997) Growing old in an information society. In Berleur, J. \& Whitehouse, D. (eds.) The ethical global information society - culture and democracy revisited. Chapman \& Hall, London, pp. 289-303.

Rathenau Institute (1996) Tussen hype, hoop en zorg. Den Haag.

Rijsselt, R.J.T. van \& Weijers, T.C.M. (1997) Ouderen en de informatiesamenleving. Otto Cramwinckel Uitgeverij, Amsterdam.

Riley, M.W. (1987) On the significance of age in sociology. American Sociological Review $1521-14$.

Salthouse, T. (1996) Implications of adult age differences in cognition for work performance. In: Work after 45?: book of abstracts. The Swedish National Board of Occupational Safety and Health, Vasterik.

Schuyt, C. (1997) Niet ieder probleem is een sociaal probleem. De Volkskrant 5-04-97. pp. 16. 
Timmermans, J.M. (ed.) (1997) Rapportage ouderen 1996. Sociaal en Cultureel Planbureau, Rijswijk.

Webster, F. (1995) Theories of the information society. Routledge, London.

Willems \& van den Wildenberg (1996) Haalbaarheidsstudie Ouderen en de elektronische snelweg. Den Haag.

Zuurmond, A. (1994) De infocratie - een theoretische en empirische heroriëntatie op Webers ideaaltype in het informatietijdperk. Phaedrus, Den Haag. 